\title{
UNA VISIÓN POCO TRIUNFALISTA DE LA UNIVERSIDAD
}

\section{A BIT TRIUMPHALIST VISION OF THE UNIVERSITY}

Marco A. López-Cerdá: Catedrático de la Universidad de Alicante ma.lopez-cerda@ual.es

\section{CURRÍCULUM VITAE}

Catedrático de Estadística e Investigación Operativa de la Universidad de Alicante (España). Sus temas de interés son la Programación Matemática, el Análisis Convexo y la Teoría de Juegos, temas en los que ha publicado más de cincuenta artículos de investigación, y ha dirigido trece tesis doctorales.

\section{RESUMEN}

En mis treinta y seis años de servicio como profesor universitario, los últimos veintisiete como catedrático, he observado un auténtico declive de la Universidad como institución. Su principal problema es que se ha politizado de manera excesiva y se te considerará o no, según tu grado de afinidad política. La gestión burocrática prima por encima de los méritos académicos en todos los sentidos.

\section{PALABRAS CLAVE}

Universidad - Profesor - Méritos - Politización 


\begin{abstract}
In my thirty-six years of service as a university professor, the last twenty seven as a professor, I have noticed a real decline of the university as an institution. Its main problem is that is excessively politicized and you will be considered or not as your degree of political affinity. The premium over bureaucratic management of academic merit in every way.
\end{abstract}

\title{
KEY WORDS
}

University - Professor - Merit - Politicization

\section{TEXTO}

Ayer mismo se me notificó la concesión del decimosegundo trienio como profesor de universidad, el que corresponde a treinta y seis años de servicio, los últimos veintisiete como catedrático. Es por ello que me permito someter a la consideración del lector algunas reflexiones sobre el proceso de deterioro grave de la institución universitaria.

Lejos de pretender llevar a cabo un análisis exhaustivo de las causas de este declive, me centraré en las que considero más generales, y que percibo con mayor intensidad. Pido disculpas a aquellos miembros de la comunidad universitaria que puedan sentirse aludidos por mis comentarios, pero ellos saben que lo que se dice aquí es la pura realidad. Algunos me acusarán de hacer "catastrofismo" y me etiquetarán políticamente, pero a este tipo de comportamientos ya estoy habituado. 
Afortunadamente para mí, conservo una total libertad de pensamiento, no obedezco a ninguna disciplina política, y voto cada vez la opción que me parece más adecuada.

Quiero comenzar incidiendo en uno de los principales males de la universidad española, la "politización" excesiva, que llega al extremo de que la consideración de que eres objeto por parte de los directivos de tu universidad depende en mayor medida de tu grado de afinidad política y no de tus méritos estrictamente profesionales. Supongan que el profesor más prestigioso de una universidad española, con categoría de premio Nobel, decidiese presentarse como candidato a las elecciones de rector, pero sin estar patrocinado por algún partido político o por algún sindicato de clase. Pues bien, es seguro que nunca ganaría las elecciones.

En algunos países avanzados las universidades "fichan" como rector a alguien de fuera de la institución, atendiendo a su prestigio y a sus éxitos profesionales previos al frente de alguna otra universidad (como hacen los clubes de fútbol). Por el contrario, en la universidad española los rectores suelen proceder de los equipos de gobierno anteriores, quizás porque desde ellos pueden controlar mejor los resortes electorales. Consecuencia de este procedimiento es que el rector, una vez "elegido", tiene su futura gestión absolutamente condicionada por los pactos, compromisos y promesas que ha tenido que suscribir para llegar al poder. Este proceso, normal en política general, tiene efectos perversos en su gestión como rector, explicando su resistencia a emprender cambios importantes, en la buena dirección, que pudiesen incomodar a sus electores.

En una ocasión escuché decir a un prestigioso profesor de la Universidad de Cambridge (Reino Unido) que el "prestigio de una universidad se basa exclusivamente en la calidad de sus alumnos, y que son los buenos alumnos los que hacen buenos a los profesores". En España, la política de creación indiscriminada de universidades, agravada por la evolución demográfica, hace que las universidades 
tengan que competir entre ellas por la captación de alumnos, los buenos y los menos buenos (no hay prácticamente selección del alumnado), pero en vez de hacerlo en base a la calidad científica de sus programas y de sus docentes, compiten en base a una política de progresivo "abaratamiento" de los títulos universitarios, y de permanentes concesiones a los alumnos. Algunas de estas concesiones resultan excesivas y adquieren tintes claramente demagógicos (enseñanza y exámenes virtuales en materias que no se prestan a ello, determinando un descenso en su nivel de calidad; aprobados por compensación; concesión de un gran número de convocatorias para pasar un examen; premios a los profesores que aprueban a un porcentaje elevado de estudiantes, etc.), rayan en la adulación al alumnado, y nada tienen que ver con el principio genérico que debiera regir la relación profesor/alumno: "el profesor debe explicar bien su asignatura y los alumnos deben estudiar lo necesario". El llamado fracaso escolar preocupa mucho a los políticos (crea malestar, y les resta votos), y la llamada convergencia al espacio europeo de educación superior (basado en los acuerdos de Bolonia) está conduciendo a una completa devaluación de las carreras. Se trata de conseguir que el "alumno apruebe más fácilmente, estudiando menos", para que, satisfaciendo los deseos de la actual ministra de educación, "sea más feliz". Se olvida que una fuente de auténtica satisfacción personal es la consecución de objetivos en la vida gracias al esfuerzo.

Hablemos ahora del profesorado. Para hacerlo con rigor hemos de partir de que la universidad española no es "competitiva". Opino que, si de una mala política de selección del profesorado (es decir, de no elegir a los mejores) se derivasen consecuencias graves para el futuro del centro como la reducción drástica de sus presupuestos, llegando incluso a su cierre (se ha hecho en muchos países), no haría falta recurrir a ningún proceso complejo de selección (habilitaciones, acreditaciones, etc.). El problema aquí es que elegir "al menos bueno" sale gratis ya que no tiene repercusión visible de inmediato; sólo que el profesor elegido impartirá clases mediocres y su investigación (si la hace) será también mediocre, contribuyendo a la 
mediocridad de su institución. Piense el lector que no hay ninguna universidad española en el grupo de las doscientas mejores del mundo, y una de las claves es el tan cacareado "principio de autonomía universitaria", el cual se basa en la siguiente argumentación: "Querido contribuyente: Déme su dinero que yo me lo gastaré en lo que considere oportuno, pero no me pida que le rinda cuentas porque entonces estaría usted vulnerando mi autonomía universitaria". Encima algunos consideran que esto es progresista cuando, en realidad, la universidad es un servicio público cuyo funcionamiento debe estar sometido al control permanente de la sociedad a la que sirve, a través de sus órganos de representación democráticos.

Al amparo de la autonomía universitaria se cometen verdaderas tropelías, y doy algunos ejemplos. Hace seis años, ante la perspectiva de que entrara en vigor la L.O.U. (Ley Orgánica de Universidades), la cual contemplaba unos procesos de selección del profesorado de carácter más competitivo, las universidades respondieron convocando más de 8.000 plazas de la noche a la mañana, las cuales fueron adjudicadas en su mayor parte a candidatos locales (¡pura endogamia!), mediante el sistema de concursos entonces vigente, en el que el candidato local contaba (salvo excepciones) desde el principio con dos votos a su favor de los cinco a emitir por el tribunal. Atropello absoluto de las legítimas aspiraciones de buenos candidatos externos que podrían haberse incorporado a nuestras universidades y contribuir a mejorar su calidad, vulneración flagrante del más elemental principio de justicia y de "universalidad" en el reconocimiento del mérito (paradójico, cuando estamos hablando de "universidad", ¿no?). Además se bloquearon por muchos años las plantillas de profesorado, impidiendo el acceso posterior de muchos jóvenes con méritos sobrados. ¿Qué empresa, pública o privada, podría haberse permitido tamaño desatino, sin ver tambalearse su propia supervivencia?

También hemos asistido con estupor al espectáculo de que muchos "profesores" aprovecharon su paso por los "cargos" para, desde ellos, "facilitarse" el camino hacia 
las cátedras, o para elaborar baremos de promoción en beneficio propio, primando como mérito académico su "gestión burocrática", cuando tampoco ellos rindieron cuentas de su propia gestión.

Dirán ustedes: "Algo debe funcionar bien en la universidad, o ¿no es así?". Por supuesto que, a pesar de todo, hay individuos y grupos en nuestras universidades que gozan de gran prestigio, que trabajan con entusiasmo, resignados muchas veces a que sus opiniones no sean valoradas ni tenidas en cuenta.

Concluiré llamando su atención sobre el siguiente fenómeno: cuando algunas universidades han fijado procedimientos de jubilación anticipada, los primeros en irse han sido los mejores profesores, los que más sufren tanta demagogia, y esto, reconocerán, agrava más si cabe el panorama actual de la universidad española. 